\title{
PRELIMINARY STUDY OF THE EFFECTS OF POST-RETRIEVAL EXTINCTION ON THE RETURN OF CONDITIONED RESPONSES IN HUMANS
}

\section{ESTUDO PRELIMINAR DOS EFEITOS DA EXTINÇÃO PÓS-RECUPERAÇÃO SOBRE O RETORNO DE RESPOSTAS CONDICIONAIS EM HUMANOS}

\author{
PEDRO FONSECA ZUCCOLO - ORCID 0000-0002-6340-6097 \\ MARIA HELENA LEITE HUNZIKER - ORCID: 0000-0003-0030-375K \\ UNIVERSIDADE DE SÃo PAULO, BRAZIL
}

\begin{abstract}
RESUMO
Conduzimos um estudo preliminar replicando o experimento de Schiller et al. (2010), que demonstraram que respostas condicionais (CRs) podem ser permanentemente inibidas pela extinção pós-recuperação, um procedimento no qual um estímulo que estava presente durante o condicionamento (pista de recuperação), tal como a apresentação isolada de um CS sem o US ou do próprio US, é apresentado antes da extinção. Onze adultos foram submetidos a condicionamento Pavloviano com três quadrados coloridos (CSs), dois dos quais ( $\mathrm{CSa}+\mathrm{e} \mathrm{CSb}+$ ) foram pareados a uma estimulação elétrica leve (US), enquanto que um terceiro estímulo nunca foi pareado ao US (CS-). Vinte e quatro horas depois, os participantes foram divididos em dois grupos (experimental e controle) e passaram por extinção, que consistiu na apresentação de todos os CSs sem o US. Apenas para o grupo experimental, uma pista de recuperação consistindo em uma única apresentação do CSa+ e CS- sem o US foi feita 10 minutos antes da extinção. Na fase de teste, o US foi administrado quatro vezes, seguido por um intervalo de 10 minutos e um novo procedimento de extinção. As respostas de condutância da pele frente à apresentação dos estímulos foram medidas. Os grupos apresentaram níveis equivalentes de condicionamento e extinção, assim como um aumento nas amplitudes da CR após apresentação de todos os estímulos na fase de teste. Estes dados não replicam os achados do estudo original, sugerindo que mais análises são necessárias para identificar as variáveis que controlam condicionamento e extinção Pavlovianos em humanos. humanos.

Palavras-chave: condicionamento Pavloviano, extinção pós-recuperação, reconsolidação, condutância da pele,
\end{abstract}

\begin{abstract}
We conducted a preliminary study to replicate the experiment by Schiller et al. (2010), who found that conditional responses (CR) may be permanently inhibited through post-retrieval extinction, a procedure in which subjects are exposed to a stimulus that was present during conditioning (retrieval cue), such as the presentation of the CS without the US or a single presentation of the US alone, followed by extinction. Eleven adult participants underwent Pavlovian conditioning with three colored squares (CS), two of which (CSa+ and $\mathrm{CSb}+$ ) were paired with a mild electrical stimulation (US), whereas a third stimulus was never paired with a US (CS-). Twenty-four hours later, the participants were divided into two groups (experimental and control) and underwent extinction, which consisted of presenting all CSs without the US. For the experimental group only, a retrieval cue consisting of a single presentation of the CSa+ and CS- without the US was administered $10 \mathrm{~min}$ before extinction. In the test phase, the US was administered four times and then followed by a ten-minute interval and a new extinction procedure. Skin conductance responses to the stimuli were measured. Groups did not differ from each other. They presented equivalent levels of conditioning and extinction as well as an increase in CR amplitudes following the presentation of all stimuli in the test phase. These data do not replicate findings from the original study, suggesting that further analyses are needed to identify variables that control Pavlovian conditioning and extinction in humans.
\end{abstract}

Key words: Pavlovian conditioning, post-retrieval extinction, reconsolidation, skin conductance, humans.

\footnotetext{
Correspondence concerning this article should be addressed to Pedro Fonseca Zuccolo, Departamento de Psicologia Experimental, Universidade de São Paulo, Avenida Prof. Mello Moraes, 1721 - Butantã CEP 05508030 - São Paulo, SP - Brasil. Email: pedrozuccolo@yahoo.com.br. This research was supported by Fundação de Apoio à Pesquisa do Estado de São Paulo (FAPESP, grant no. 2011/18516-8 and 2011/16088-9), Coordenação de Aperfeiçoamento de Pessoal de Nível Superior (CAPES, grant PROEX0039047), and Conselho Nacional de Desenvolvimento Científico e Tecnológico (CNPq, grant no. 304239/2013-5).
} 
Since the pioneering work of Pavlov (1927), laboratory studies have demonstrated that an initially innocuous stimulus may acquire eliciting function, that is, it may act as a conditional stimulus (CS) after being associated with an unconditional stimulus (US). This eliciting function may be lost if the CS occurs systematically in the absence of the US. The acquisition and reduction of this eliciting function by the stimulus are called Pavlovian conditioning and extinction, respectively (Rescorla, 1988). The literature on classical conditioning further shows that the extinction of conditional responses (CRs) is not permanent and that these responses may return 1) after the passage of time (spontaneous recovery, Schiller et al., 2008); 2) after the presentation of the CS in a different context than the setting in which extinction took place (renewal, Bouton \& Bolles, 1979a, 1979b); and 3) after re-exposure to the US alone (reinstatement, Rescorla \& Heth, 1975).

It is suggested that the fear and anxiety described in some psychopathologies are CRs that may be elicited by aversive CSs and that they acquired this function as a consequence of a history in which they were paired with aversive or traumatic USs (Schiller et al., 2008; Vervliet, Craske, \& Hermans, 2013). Consistent with this analysis, some behavioral treatments for anxiety disorders attempt to reproduce Pavlovian extinction in the clinical setting (LeDoux, 2014). One such example is exposure therapy, which consists of exposing patients to feared situations, objects, and images in the absence of aversive or threatening outcomes with the goal of reducing fear reactions to those stimuli (Foa \& McLean, 2016). One limitation of exposure-based treatments, similar to results from the laboratory, is that fear and anxiety responses may reappear after an intervention involving an apparent successful extinction process, a phenomenon that has been termed return of fear (Vervliet et al., 2013). Therefore, both for research and therapeutic purposes, several studies have attempted to identify variables that control the extinction and return of extinguished CRs (Schiller et al., 2008; Vervliet et al., 2013). Thus, the question is whether it is possible to produce extinction that is not followed by the return of the $\mathrm{CR}$.

Inspired by research on the brain mechanisms of memory, researchers have developed a procedure that was shown to prevent return of conditioned responses, namely, post-retrieval extinction (PRE, Monfils, Cowansage, Klann, \& LeDoux, 2009; Schiller et al., 2010). This procedure consists of exposing subjects to a stimulus that was present during conditioning (retrieval cue), such as an unreinforced presentation of the CS or a single presentation of the US alone, followed by extinction (Liu et al., 2014; Monfils et al., 2009; Schiller et al., 2010). The hypothesis underlying this procedure is that the presentation of a retrieval cue can return a memory to a labile state for a period of time (around six hours) during which it is more susceptible to change by pharmacological or behavioral interventions (Lee, Nader, \& Schiller, 2017). Therefore, conducting extinction during this period is likely to reduce the probability of return of fear (see Lee et al., 2017 for a thorough review on the subject).
The first experiments on PRE were conducted in rats (e.g., Monfils et al., 2009) but given the applied potential of finding a procedure that permanently inhibits conditioned fear responses in clinical settings, the next logical step was to test whether this phenomenon could be demonstrated in humans. The first study to test postretrieval extinction in humans was conducted by Schiller et al. (2010). In a first experiment, they exposed participants to three experimental phases separated by $24 \mathrm{~h}$. In the first phase, participants underwent a differential Pavlovian conditioning procedure in which one visual stimulus was paired with the US in $38 \%$ of the trials (CS+), whereas another visual stimulus was never paired with the US (CS-). Visual stimuli serving as CSs were colored squares displayed on a computer screen and the US was a mild electrical shock to participants' right inner wrist. During the second phase of the experiment, participants were divided into three groups $(10 \mathrm{~min}$, 6h, and no reminder groups). Two groups (10 $\mathrm{min}$ and $6 \mathrm{~h}$ groups) were exposed to an isolated presentation of the CS+ without the US (retrieval cue), followed by a 10-min interval during which participants watched a TV show episode previously selected by the researchers. After this interval, the 10-min group underwent an extinction procedure consisting of 10 presentations of $\mathrm{CS}+$ and 11 presentations of CS- without the US; the 6-h group received the same treatment as the 10-min group, but extinction was conducted $6 \mathrm{~h}$ after the retrieval cue. The remaining group (no reminder group) began the session by watching the TV program for $10 \mathrm{~min}$. For half of these subjects, extinction followed immediately after this 10min period; for the other half, extinction was conducted 6 $\mathrm{h}$ after watching the TV show. To ensure that participants from all groups were exposed to the same number of CSs, extinction in the no reminder groups consisted of 11 presentations of each CS without the US. In the third phase of the experiment, all participants were exposed to 11 presentations of each CS without the US. The results showed that only subjects whose interval between the retrieval cue and extinction was $10 \mathrm{~min}$ did not show recovery of conditioned responses, as measured though skin conductance responses. The results were the same after one year, when 19 of the 65 original participants underwent a procedure in which four unsignaled presentations of the US were made, which was followed by extinction (reinstatement test).

Schiller et al. (2010) conducted a second experiment to test whether interfering with the eliciting function of one CS would affect the eliciting function of another CS associated with the same US. Three CSs (colored squares) were used in a within-subject design. Two squares (CSa+ and $\mathrm{CSb}+$ ) were paired with the US (in $38 \%$ of presentations), and the third was never paired (CS-) in the first day. On the following day, participants underwent extinction. At the start of the session, one CSa+ and the CS- were presented without the US (retrieval cues), which was followed by a 10-min interval, during which participants watched an episode from a TV show. After this interval, participants were exposed to 10 presentations of $\mathrm{CSa}+$ and $\mathrm{CS}-$ and 11 presentations of $\mathrm{CSb}+$. They 
conducted a test on a third day in which the US (without the CS) was presented four times. After a 10-min interval, during which participants watched the same television episode as on the previous day, a new extinction procedure was carried out (11 presentations of each of the three CSs alone). Conditioned responses, as measured through skin conductance responses to the CSs, were only observed to the $\mathrm{CSb}+$.

Results from Schiller et al. (2010) suggest that reduction of CRs might be long lasting if extinction is conducted after the presentation of a retrieval cue. These data also indicate that the timing of extinction relative to the presentation of the retrieval cue is important, as intervals longer than $6 \mathrm{~h}$ between retrieval cue and extinction might render the procedure ineffective in preventing the return of fear.

Since the publication of Schiller et al. (2010), several studies were able to show that PRE might prevent the return of fear in humans (Agren et al., 2012; Asthana et al., 2015; Bjorkstrand et al., 2015; Johnson \& Casey, 2015; Liu et al., 2014; Oyarzún et al., 2012; Schiller, Kanen, LeDoux, Monfils, \& Phelps, 2013; Thompson \& Lipp, 2017). Some of these studies were direct replications (e.g., Schiller et al., 2013), whereas others have manipulated different aversive stimulus utilized as US (e.g., Oyarzún et al., 2012) or the type of retrieval cue (e.g., Liu et al., 2014) (see Zuccolo and Hunziker, 2019 for a review).

There have also been reports of failure in preventing return of fear using PRE (e.g., Fricchione et al., 2016; Golkar, Bellander, Olsson, \& Öhman, 2012; Kindt \& Soeter, 2013; Klucken et al., 2016; Kredlow, Orr, \& Otto, 2018a; Meir Drexler et al., 2014; Soeter \& Kindt, 2011). These replication failures have been discussed in terms of boundary conditions, that is, conditions under which PRE is thought not to be effective. Variables discussed as possible boundary conditions to the long lasting reduction of $\mathrm{CR}$ after PRE include preexperimental characteristics of participants (genetic or psychiatric), conditions that change the strength of conditioning (time since initial learning, the percentage and/or number of CS-US pairings, the nature of CS, or the instruction during experimental phases), the retrieval procedures (the type of retrieval cue, for example), as well as the response systems assessed (Zuccolo and Hunziker, 2019). As the limits of some of these variables as well as their interactions are unknown, work is still needed in this area.

Considering the clinical implications of a procedure that helps prevent the return of conditioned responses after extinction, our laboratory aimed at initiating a series of experiments to identify variables determining the effects of PRE. Given the reported difficulties in replicating the effects of PRE and the fact the this was the first study on PRE conducted by our laboratory, we sought to replicate the most discussed experiment in the area, namely, Schiller et al. (2010, Experiment 2). Specifically, we sought to verify whether PRE might reduce the reoccurrence of the CR after extinction.

\section{METHODS}

\section{Participants}

Adults were recruited from the undergraduate and graduate populations of two universities in Sao Paulo, Brazil, through online advertisements on and off campuses. All volunteers underwent a screening interview prior to the experiment to verify whether they were free from any conditions, medical or otherwise, that would contraindicate participation in the study (i.e., reported cardiovascular disease or epileptic seizures, cutaneous lesions in the areas of electrode attachment, presence of a pacemaker or any other metal implant, pregnancy, or current use of psychoactive medications during the experiment, and whether they could discriminate the colors yellow, red, blue, orange, purple, and green). From a total of 35 participants eligible for the study, eleven were included in the final analysis (eight males and three females, mean age $25 \pm 5$ years). Twenty-two participants had to be excluded because they did not meet three standard criteria used in studies on PRE with skin conductance as dependent measure: (1) measurable skin conductance responses in all experimental phases $(n=2)$, (2) evidence of conditioning $(n=17)$; and (3) evidence of extinction $(n=3)$ (see Criteria for conditioning and extinction for details). These criteria have been used by several laboratories in the area because it is only possible to assess return of a conditioned response if it has been conditioned in the first place and diminished after extinction (Schiller et al., 2013). Additionally, 2 participants refrained from the experiment (dropout).

All participants gave informed consent prior to the experiment. All procedures were approved by the Ethics Committee of the Faculty of Philosophy, Sciences, and Languages of Ribeirao Preto (FFCLRP), University of Sao Paulo (process CEP-FFCLRP n ${ }^{\circ}$ 594/2011 2011.1.1817.59.3).

\section{Apparatus and stimuli}

The US was a mild and brief electrical shock (200 ms duration, $50 \mathrm{~Hz}, 10$ to $60 \mathrm{~V}$ ) delivered to the right inner wrist of participants through a bipolar electrode measuring $8 \mathrm{~mm}$ in diameter with $21 \mathrm{~mm}$ of separation between poles connected by a ribbon strap. A Grass Medical Instruments (West Warrick, Rhode Island, USA) S48 stimulator and a SIU5 stabilizer were used. The intensity of the US was set according to each participant's tolerance level (see Experimental Procedure).

The CSs included three pictures of colored squares. For half of the participants, the colors of the squares were yellow, red, and blue (Set 1), whereas the squares were orange, purple, and green (Set 2) for the other half. These squares measured $11.5 \times 11.5 \mathrm{~cm}$ and were presented on a 21.5 " computer monitor with a black background.

Skin conductance responses were recorded using a conductive gel and two disposable $\mathrm{Ag}$-AgCL electrodes that were connected to a GSR100C BioPac Systems (Goleta, California, USA) skin conductance module. The data were analyzed offline using the AcqKnowledge 4.2 software on a notebook with an Intel(r) Core i5 processor. 
The experiment was programmed using SuperLab 4.5.3 software (Cedrus, San Pedro, California, USA), which was run on a separate PC with an Intel processor. Data collection was conducted in a room located in the Biobehavioral Analysis Laboratory, which was equipped with a window, desk, and chair (Psychology Institute, University of Sao Paulo).

\section{Experimental procedure}

The experiment consisted of three consecutive sessions that were conducted approximately $24 \mathrm{hr}$ apart and in the following order: conditioning, extinction, and test. The participants were randomly assigned to one of two groups, experimental or control. The two groups differed only with regards to the extinction procedure.

At the beginning of each experimental session, the participant was asked to wash his / her hands with water (no soap) and dry them with paper towel. Afterwards, he / she was taken to the testing room where he / she sat in front of a computer monitor. The equipment for recording data and controlling experimental procedures was located behind the participant. The experimenter installed the stimulating electrodes on the participant's right inner wrist, attaching it with the ribbon strap in a position parallel to the forearm and verifying that both poles were in contact with the participant's skin. Skin conductance electrodes were connected to the distal phalanges of the middle and index fingers of the left hand. The stimulating electrode was cleansed with alcohol gel prior to attachment. With the exception of breaks that were given during the extinction and test sessions (detailed herein), subjects remained connected to the stimulating and skin conductance electrodes.

Once the participant was attached to the electrodes, the room was dimly illuminated, and skin conductance acquisition was initiated. The intensity of the electrical stimulation used as unconditional stimulus was established in the first session according to each participant's tolerance, which was determined by asking participants to indicate their tolerance level to the applied stimulus. An optimal tolerance level was one that was deemed uncomfortable but not painful according to the participant. The initial level of the stimulation was $10 \mathrm{~V}$, which was increased in $5 \mathrm{~V}$ steps until the participant indicated that his / her tolerance level had been reached. The maximum level of stimulation was $60 \mathrm{~V}$, which has been shown to be within a safe range of stimulation for human participants (Schiller, Raio, \& Phelps, 2012; Zeidan et al., 2012). Once the level of stimulation was calibrated, it remained unaltered for the remainder of the experiment.

After these preparatory steps, the procedures specific to each experimental session were implemented.

\section{Session 1 - Conditioning}

The experimenter gave the following instructions: "The objective of this experiment is to assess how your sweat glands react to sensory, visual, and tactile stimuli. You do not have to do anything with your hands or use the mouse or keyboard. You just have to look at the computer screen and pay attention to the things you are seeing and to the things you are feeling. Any questions?"

Once the participant said he /she understood the instructions, the session began. Participants underwent a differential Pavlovian conditioning in which two CSs (hereafter termed $\mathrm{CSa}+$ and $\mathrm{CSb}+$ ) were intermittently paired with the US, whereas a third CS (CS-) was never paired with the US. Specifically, each CS was presented 16 times, for a total of $48 \mathrm{CS}$ presentations, and the US was presented 16 times. Each CS was presented for $4 \mathrm{~s}$, and the US was presented for $0.2 \mathrm{~s}$. In the beginning of the experimental session, each CS was presented three times without the US (habituation), followed by four presentations of each $\mathrm{CS}$, with the $\mathrm{CSa}+$ and $\mathrm{CSb}+$ being systematically paired with the US (100\% pairing). In the last part of the session, each CS was presented nine times, with the $\mathrm{CSa}+$ and $\mathrm{CSb}+$ being paired four times with the US (45\% pairing). In this part of the experimental session, paired presentations of the CS were randomized, and thus, they were distributed evenly along with non-paired presentations of CSs. CS-US pairing corresponded to the presentation of the US in the last $0.2 \mathrm{~s}$ of the CS presentation, so that the two stimuli co-terminated. The session terminated after the last CS presentation. The session duration was approximately 20 minutes.

Each CS presentation corresponded to a trial. The period during which the computer screen went black corresponded to an inter-trial interval (ITI) that was $13 \mathrm{~s}$, on average, (varying from $12 \mathrm{~s}$ to $14 \mathrm{~s}$ ) during which no experimental manipulation was programed. During conditioning, CSs were presented in a pseudo-random schedule that prevented the presentation of the same stimulus more than two times in a row.

\section{Session 2 - Extinction}

The following instructions were given. "Similar to yesterday, you do not have to do anything with your hands or use the mouse or keyboard. You just have to look at the computer screen and pay attention to the things you are seeing and to the things you are feeling. Any questions?" Following these instructions, there were 45 non-paired presentations of the CS (15 times for each CS), with a different procedure for each experimental group, as follows.

Experimental group. After a single presentation of the CSa+ and CS- (in counterbalanced order across subjects), the computer screen went black, and the following instructions were given: "We now will have a ten-minute break. Here are some magazines that you may choose to read during the break. You do not have to read anything if you do not want to. The only thing that is important is that you take your break in the specified location where I take you. However, first, I will turn off and disconnect you from these devices". The subject was disconnected from the electrodes, the stimulator was set to the "Off" position, and the participant was taken to a waiting room with chairs and magazines. During the tenminute period, subjects were required to remain in the room. They were allowed to use the restroom providing they returned to the waiting room afterwards. Subjects were 
asked not to consume food or beverages (including coffee) and were prohibited from smoking cigarettes. Once the tenminute period was over, participants were returned to the testing room, and the following instructions were given: "We have finished the ten-minute break. I will now reconnect these devices, and we will complete the remainder of the session". Subjects were reconnected to the electrodes, and the stimulator was set to the "On" position. The session was resumed with the remaining presentations of the CSs (i.e., $14 \mathrm{CSa}+, 15 \mathrm{CSb}+$, and $14 \mathrm{CS}$-).

Control group: All procedures were identical to the ones described for experimental group (i.e., they were exposed to the 45 presentations of the CSs using the same duration and ITIs), with the exception of the ten-minute break, which was not conducted for this group. The duration of the session for the control group was approximately 15 min, whereas that for the experimental group was approximately $25 \mathrm{~min}$.

\section{Session 3 - Test}

The following instructions were given. "Similar to yesterday, you do not have to do anything with your hands or use the mouse or keyboard. You just have to look at the computer screen and pay attention to the things you are seeing and to the things you are feeling. Any questions?" Following these instructions, we conducted a reinstatement test, which consisted of presenting the US alone four times while the computer screen remained black with ITIs varying from $12 \mathrm{~s}$ to $14 \mathrm{~s}$. Subsequently, subjects were given a tenminute break, similar to the one in the extinction session, after which they returned to the testing room where the electrodes were reconnected, the stimulator was turned to the "On" position, and the CSs were presented 15 times each without the US, for a total of 45 CS presentations. The stimuli presentation was randomized in a similar fashion to the previous sessions, with the difference that the CS- was always the first stimulus to be presented. The responses to this first presentation were not included in the analysis ${ }^{1}$. The duration of this session was approximately 28 minutes. The experimental design is summarized in Table 1.

\section{Skin conductance assessment}

Prior to the analysis, skin conductance recordings were filtered using a low-pass filter and were smoothed to eliminate artifacts in the signal. The amplitudes of the skin conductance responses to the US or CS were determined manually by taking the base to peak difference of the largest waveform (in microsiemens, $\mu \mathrm{S}$ ) initiated in the 0.5 to $4.5 \mathrm{~s}$ period after stimulus onset. The minimal response criterion was $0.02 \mu \mathrm{S}$. Increases in skin conductance below $0.02 \mu \mathrm{S}$, decreases in skin conductance, and stable recordings during this 0.5 to $4.5 \mathrm{~s}$ interval were scored as zero and were included in the analysis.

\footnotetext{
1 This procedure was utilized because the first stimulus presentation usually elicited an increase in skin conductance regardless of its nature, that is, regardless of whether it was a $\mathrm{CS}+$ or CS-. The effect is termed an "orienting response" (Boucsein, 2012; Schiller et al., 2013).
}

CRs were measured only for non-paired presentations of the CS. Unconditional responses (URs) were measured taking the base to peak difference of the largest waveform initiated 0.5 to $4.5 \mathrm{~s}$ after US onset. Because the data were manually selected, the experimenter was blind as to which CS had been presented. That is, when the waveforms were being selected, the experimenter knew that a paired or non-paired CS had occurred, but no information was available regarding which CS had been presented, that is, whether it was a $\mathrm{CSa}+, \mathrm{CSb}+$, or CS-.

The values of the raw skin conductance responses were square root transformed to normalize distributions. Each resulting value was divided by the mean square root transformed US response. This last procedure was conducted to obtain a relative measure of conditional responses based on each participant's unconditional response (Olsson, Ebert, Banaji, \& Phelps, 2005).

\section{Criteria for conditioning and extinction}

The conditioned response was defined as the differential skin conductance response, which was calculated by subtracting responses to the CS- from responses to the $\mathrm{CSa}+$ or $\mathrm{CSb}+$ in corresponding trials. Criteria for conditioning and extinction were based on the differential responses as used in previous studies (Liu et al., 2014; Oyarzún et al., 2012; Schiller et al., 2010, 2012). Specifically, participants were classified as being conditioned if they presented a differential response $\geq 0.1 \mu \mathrm{S}$ to both $\mathrm{CS}+\mathrm{s}(\mathrm{CSa}+>\mathrm{CS}-\mathrm{AND} \mathrm{CSb}+>\mathrm{CS}-)$ in the last five presentations of the CSs during conditioning. Additionally, participants were required to show equivalent levels of conditioning between CS+s (i.e., the difference between $\mathrm{CR}$ to the $\mathrm{CSa}+$ and $\mathrm{CSb}+$ could not be greater than $0,1 \mu \mathrm{S}$ ). For extinction, the criteria were the opposite, that is, participants were required to show average differential response $<0.1 \mu \mathrm{S}$ in the last trial of extinction $(\mathrm{CSa}+<\mathrm{CS}-\mathrm{AND} \mathrm{CSb}+<\mathrm{CS}-$ ).

\section{Data analysis}

Because the final analysis included few subjects, statistical analyses were conducted using non-parametric tests to identify possible tendencies within the variables of interest. We adopted a significance level of $\alpha=5 \%$ for all analyses. The following tests were used: 1) Friedman test for the conditioning session to compare mean CRs within each group; 2) Wilcoxon test to compare a) the mean CRs to the $\mathrm{CSa}+\mathrm{CSb}+$, and $\mathrm{CS}$ - in the conditioning session with the last responses to the same stimuli in the extinction session, b) the last response to the stimuli in the extinction session with the first responses in the test session, and c) the first response to each stimulus with the subsequent ones in the extinction and test sessions (to verify whether there were differences between stimuli in the speed of extinction); and 3) Mann-Whitney test to compare groups regarding responses to each of the stimuli (CSa+, $\mathrm{CSb}+$, and $\mathrm{CS}-)$ in all experimental sessions. 
Table 1.

Experimental design and timeline

Session 1

Session 2

Session 3

(Conditioning)

(Extinction)

\begin{tabular}{|c|c|c|c|}
\hline $\begin{array}{c}\text { Experimental and control } \\
\text { groups }\end{array}$ & Experimental group & Control group & $\begin{array}{c}\text { Experimental and control } \\
\text { groups }\end{array}$ \\
\hline $3 \mathrm{CSa}+, 3 \mathrm{CSb}+, 3 \mathrm{CS}-$ & $1 \mathrm{CSa}+1 \mathrm{CS}-$ & $15 \mathrm{CSa}+, 15 \mathrm{CSb}+, 15 \mathrm{CS}-$ & $4 \mathrm{US}$ \\
\hline $\begin{array}{c}4 \mathrm{CSa}+\mathrm{e} 4 \mathrm{CSb}+ \\
\text { (with US } 100 \% \text { of times), } \\
4 \mathrm{CS}-\end{array}$ & (10 min interval) & & (10 min interval) \\
\hline $\begin{array}{c}\text { 9CSa+, 9CSb+ } \\
\text { (with US } 45 \% \text { of times), } \\
\text { 9CS- }\end{array}$ & $14 \mathrm{CSa}+, 15 \mathrm{CSb}+\mathrm{e} 14 \mathrm{CS}-$ & & $15 \mathrm{CSa}+, 15 \mathrm{CSb}+, 15 \mathrm{CS}-$ \\
\hline
\end{tabular}

\section{RESULTS}

No differences were found between groups regarding US intensity, specifically, a mean of $28.3 \mathrm{~V}( \pm 3.5)$ and $25.1( \pm 6.3)$ for control and experimental groups, respectively. As no systematic effects were found as a function of CSs color, the variables are treated here as $\mathrm{CSa}+$, $\mathrm{CSb}+$, and CS-, regardless of color.

Figure 1 shows mean skin conductance amplitudes (in microsiemens, $\mu \mathrm{S}$ ) to the CSs throughout the three sessions demonstrated by subjects from control and experimental groups. During conditioning, response amplitudes to the two CSs+ were greater than the response amplitudes to the CS- $(p<0.05)$. There were no systematic differences between responses elicited by the $\mathrm{CSa}+$ and $\mathrm{CSb}+$ (control: $\chi^{2}(2)=7.6, p=0.022$; experimental: $\chi^{2}(2)=9.0, p$ $=0.011)$.

No differences were found between groups in the extinction session, with both groups showing high skin conductance amplitudes in the first trials, especially with regards to the CSs+. A gradual reduction in responses throughout trials eventually reached an absence of responses (zero amplitude) in the final presentation of each CS. Moreover, in the comparison of mean responses to the CSs in the conditioning and extinction sessions, statistically significant differences were found for both groups $(p<0.05)$.

In the test session, although an increase in CR amplitudes to all stimuli was observed in comparison to the extinction session, these differences were not statistically significant. As in the extinction session, there was a systematic reduction in CR amplitudes to the CSs in both groups, with a difference observed in extinction speed. Whereas participants from the control group demonstrated predominantly high response amplitudes (similar to the levels in the conditioning session) with great variation throughout the session and with low amplitudes at the end of the session, participants from the experimental group demonstrated a rapid reduction in response amplitudes after the second trial, a finding that was accentuated in subsequent trials; furthermore, the experimental group exhibited no responses (zero amplitude) to the three CSs in the final trial. However, in both groups, differences between the first and the remaining CRs in the test were not statistically significant. It is further noted that in the last two sessions, both groups showed response amplitudes to the CS- that were similar to the pattern exhibited for the CSs+, with no differences between responses elicited by the three stimuli.

\section{DISCUSSION}

As expected, given our selection criteria, the results from the first two sessions fulfilled criteria for the study of return of CRs after extinction. In the test session, however, results did not replicate the differential effects described by Schiller et al. (2010). It was expected that participants from the experimental group would show less return of CRs to the $\mathrm{CSa}+$ in comparison with the $\mathrm{CSb}+$, whereas subjects from the control group were expected to show return of CRs to both $\mathrm{CSa}+$ and $\mathrm{CSb}+$. However, our results indicate that in the first trial, participants from both groups showed an increase in responses to all CSs+. Therefore, we were not able to demonstrate that PRE might alter the reoccurrence of $\mathrm{CR}$, which is consistent with several experiments that were not able to obtain results described by Schiller et al. (2010) (e.g., Fricchione et al., 2016; Golkar et al., 2012; Kindt \& Soeter, 2013; Klucken et al., 2016; Kredlow et al., 2018a; Meir Drexler et al., 2014; Soeter \& Kindt, 2011).

Aside from the behaviors of participants from both groups regarding the CSs+ presentations as being indistinguishable, we observed an increase in response amplitudes to the CS-, which was never paired with the US in either the extinction or the test sessions. This result raises the question of which process controls the conditioned responses. When considering only a history of conditioning (i.e., pairings of the CSs+ with the US), why would there be such an increase in responses to the CS-, which was never paired with the US? A generalized return of conditioned responses, defined as an increase in responses to the CS+ and the CS- to the same degree in the test, has been observed in several studies using standard extinction procedures, especially when a reinstatement test such as the one used here is performed (Dirikx, Vansteenwegen, Eelen, \& Hermans, 2009; Haaker, Golkar, Hermans, \& Lonsdorf, 2014; Kull, Müller, Blechert, Wilhelm, \& Michael, 2012; Sokol \& Lovibond, 2012). 

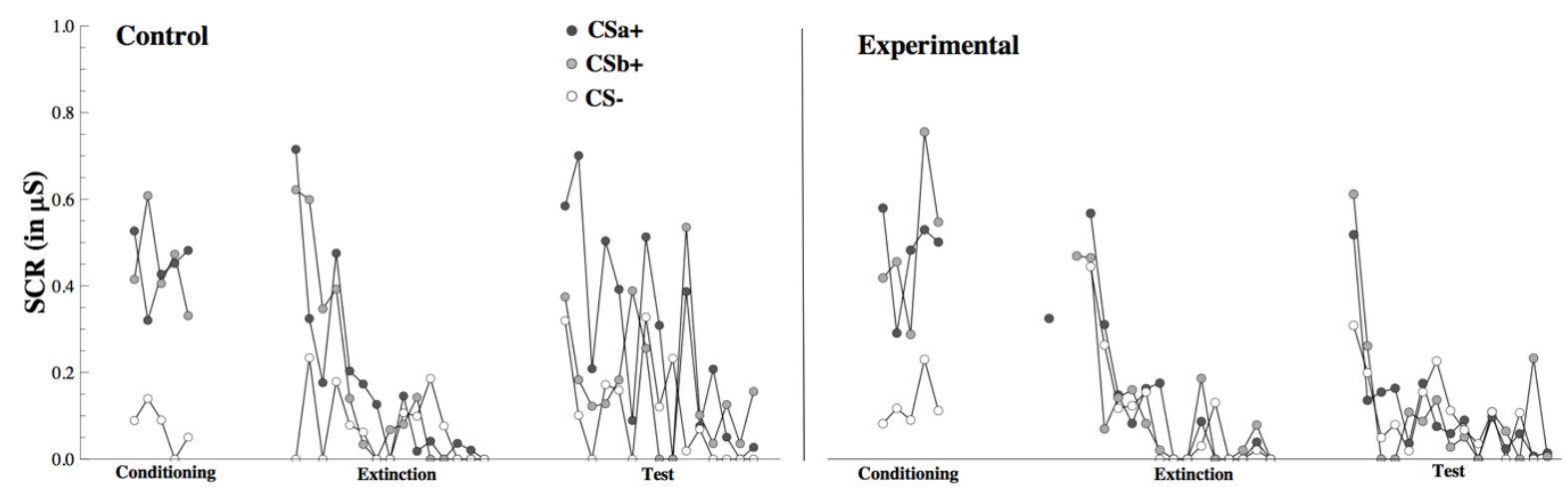

Figure 1. Mean $\mathrm{CR}$ amplitudes for $\mathrm{CSa}+\mathrm{CSb}+$, and $\mathrm{CS}$ - throughout conditioning (mean of the five presentations of the CSs+ unpaired with US and last five presentations of the CS-), extinction, and test. The left panel shows data from control group, and the right panel shows data from the experimental group. The isolated plot in experimental group represents the conditional response to single presentation of the $\mathrm{CSa}+$ (with a ten-minute interval) in the beginning of the extinction phase. Statistically significant differences were found between CSa+ and CS- and between CSb+ and CS- during the conditioning phase for both groups $(p<0.05)$.

The variables involved in increased responsivity to the CS- in reinstatement tests has been a matter of debate in the literature (Vervliet et al., 2013). Some experiments have associated this phenomenon with higher levels of self-reported trait anxiety (Kindt, Soeter, \& Vervliet, 2009; Soeter \& Kindt, 2010). According to Vervliet et al. (2013), increased responses to the CS- after reinstatement tests in anxious participants might be related to two mechanisms: 1) generalization of the conditioned fear responses to the CS+ or 2) conditioning to the entire context after presentations of the US, so that any stimulus presentation will induce increased reactivity. These mechanisms were hypothesized in light of experimental data showing that discrimination between CS+ and CS- is more difficult to occur in anxious subjects (Grillon, 2002). Moreover, anxious participants are more likely to present generalization of conditioned responses to stimuli sharing physical features with the CS+ (Kaczkurkin et al., 2016). The decision to use a reinstatement test in the present experiment was driven by the fact that this design is used by several experiments on PRE in humans (Agren, Björkstrand, \& Fredrikson, 2017; Agren et al., 2012; Golkar et al., 2012; Johnson \& Casey, 2015; Klucken et al., 2016; Kredlow et al., 2018a; Oyarzún et al., 2012; Schiller et al., 2013, 2010; Steinfurth et al., 2014). However, in our study, subjects did not undergo psychiatric assessment nor were any measures of anxiety considered, which prevents an analysis of any relationship between anxiety levels and CRs. That said, it would be important for future studies to use a more robust selection of participants taking into account the possible effect of pre-experimental characteristics on conditioned responses. Although the presence of psychiatric symptoms has been shown to influence behavioral patterns related to Pavlovian conditioning and extinction (Grillon, 2002), the criteria for selecting participants has not been described in several papers on PRE in humans (Zuccolo \& Hunziker, 2019). In fact, only recently the effects of pre-experimental characteristics of participants on conditioning, extinction, and return of conditioned responses has been thoroughly discussed (Kredlow, Orr, \& Otto, 2018b; Lonsdorf et al., 2017).

Since this is a preliminary study, it is important to address some of its limitations. One factor that might have contributed to the failure to replicate Schiller et al. (2010) is related to the reduction of our sample after applying criteria for conditioning and extinction, which substantially reduced the power to show differences between groups (and between responses to different stimuli within groups). Approximately $2 / 3$ of the initial participants had to be excluded from the analysis because the assessment of the return of a conditioned response requires demonstrating that a) the behavior of interest (differential conditioning to the $\mathrm{CSa}+$ and $\mathrm{CSb}+$ ) was present after the first session and $b$ ) that this behavior was reduced at the end of the extinction session. Also, because we chose to use two CS+s, participants were required to show equivalent levels of conditioning between them. The criteria utilized here has been a standard in the literature, as well as the problems arising from the exclusion of many participants. In fact, the rate of exclusion of participants because of a failure to demonstrate conditioned responses using aversive stimuli as US can vary from $15 \%$ to $60 \%$ in the literature (e.g., Kredlow et al., 2018b; Lonsdorf et al., 2017; Schiller et al., 2013, 2010).

The difficulty to demonstrate conditioning in humans has been a matter of debate in the literature and there has been some works discussing this issue (Kredlow et al., 2018b; Lonsdorf et al., 2017). For example, a recent study has shown that African Americans were less likely to fulfill criteria for conditioning compared with nonAfrican-Americans; however, age, education, and gender did not predict failure to condition (Kredlow et al., 2018b). Our sample included participants from multiple racial 
groups, which could have theoretically influenced our rate of conditioning. However, this is only hypothetical, as there are no published data on the influence of race on Pavlovian conditioning in the Brazilian population, which differs in many aspects from the Americans (from which the data from Kredlow et al., 2018b were derived). Future studies should address the issue of whether and how race / skin color and other socio-demographic variables influence Pavlovian conditioning and extinction in our population.

Another factor that might have been changed our rate of conditioning is related to the type and intensity of the US. As in most studies on Pavlovian conditioning in humans, we utilized electric shocks as US. However, for ethical reasons, it is common practice in human research to make each participant choose the US intensity, rather than the experimenter setting the same intensity for all participants, as was done in earlier studies (e.g., Spence, Haggard, \& Ross, 1958). Although these procedure is ethically important, it might diminish the robustness of the conditioning phenomenon (Boucsein, 2012). Another problem arises from the fact the US intensity is set by the participant, which can increase the level controllability, a variable that has been shown to interfere with the aversiveness of a stimulus (Grillon, Baas, Lissek, Smith, \& Milstein, 2004). Given the problems of using electrical shocks as US, some laboratories have attempted to use alternative forms of aversive stimulation. For example, Oyarzún et al. (2012) utilized auditory stimuli (loud shrill sounds set at $96 \mathrm{~dB}$ ). Although they were able to replicate the results from Schiller et al. (2010), the use of an alternative to electrical shocks as US did not prevent the exclusion of approximately $20 \%$ of the sample because of failure to demonstrate conditioning (Oyarzún et al., 2012). However, a recent study showed that using a compound US (electric shock combined with a scream noise) almost doubled the rate of participants fulfilling criteria for conditioning (Kredlow et al., 2018b). In conclusion, there has been an increasing recognition from the scientific literature that a better description of the optimal parameters to produce conditioning using aversive US are needed. As such, it can be said that studies on behavior analysis aiming to improve conditioning and extinction in humans are welcome.

The study by Schiller et al. (2010) has made an enormous contribution by demonstrating that the reoccurrence of $\mathrm{CR}$ may be reduced through manipulations in the environment during extinction. However, negative results in this preliminary study adds to the literature to show that the procedure proposed by Schiller et al. (2010) must be reassessed to identify what aspects of it are essential for a reduction of return of CRs. This identification could optimize the procedure proposed by Schiller et al. (2010) and thereby facilitate its replication in different laboratories. This will require a refinement of PRE procedures as well as basic research on the optimal parameters to produce classical conditioning and extinction in participants from our population.

\section{DECLARATION OF CONFLICT OF INTEREST}

The authors declare that there is no conflict of interest regarding the publication of this article.

\section{CONTRIBUTION OF EACH AUTHOR}

P. F. Zuccolo designed the experiment, collected the data and analyzed them, and wrote the manuscript; $M$. H. L. Hunziker supervised the development of the methodological design of the experiment, analyzed the data, and wrote the manuscript.

\section{COPYRIGHT}

This is an open article and may be freely reproduced, distributed, transmitted or modified by anyone provided it is used for non-commercial purposes. The work is made available under the Creative Commons 4.0 BY-NC license.

\section{(cc) $\mathrm{BY}-\mathrm{NC}$}

\section{REFERENCES}

Agren, T., Björkstrand, J., \& Fredrikson, M. (2017). Disruption of human fear reconsolidation using imaginal and in vivo extinction. Behavioural Brain Research, 319, 9-15. doi: 10.1016/j.bbr.2016.11.014

Agren, T., Engman, J., Frick, A., Björkstrand, J., Larsson, E.-M., Furmak, T., \& Fredrikson, M. (2012). Disruption of reconsolidation erases a fear memory trace in the human amygdala. Science, 337(6101), 1550-1552. doi: 10.1126/science. 1223006

Asthana, M. K., Brunhuber, B., Mühlberger, A., Reif, A., Schneider, S., \& Herrmann, M. J. (2015). Preventing the return of fear using reconsolidation update mechanisms depends on the met-allele of the brain derived neurotrophic factor Val66Met polymorphism. International Journal of Neuropsychopharmacology, pyv137. doi: 10.1093/ijnp/pyv137

Bjorkstrand, J., Agren, T., Frick, A., Engman, J., Larsson, E.-M., Furmark, T., \& Fredrikson, M. (2015). Disruption of memory reconsolidation erases a fear memory trace in the human amygdala: An 18-month follow-up. PLoS ONE, 10(7), e0129393. doi: 10.1371/journal. pone.0129393

Boucsein, W. (2012). Electrodermal activity (2nd ed.). New York: Springer.

Bouton, M. E., \& Bolles, R. C. (1979a). Contextual control of extinction of conditioned fear. Learning and Motivation, 10, 445-466. doi: 10.1016/00239690(79)90057-2

Bouton, M. E., \& Bolles, R. C. (1979b). Role of conditioned contextual stimuli in reinstatement of extinguished fear. Journal of Experimental Psychology: Animal Behavior Processes, 5(4), 368378. doi: 10.1037/0097-7403.5.4.368

Dirikx, T., Vansteenwegen, D., Eelen, P., \& Hermans, D. (2009). Non-differential return of fear in humans after 
a reinstatement procedure. Acta Psychologica, 130(3), 175-182. doi: 10.1016/j.actpsy.2008.12.002

Foa, E. B., \& McLean, C. P. (2016). The efficacy of exposure therapy for anxiety-related disorders and its underlying mechanisms: The case of OCD and PTSD. Annual Review of Clinical Psychology, 12(1), 1-28. doi: 10.1146/annurev-clinpsy-021815-093533

Fricchione, J., Greenberg, M. S., Spring, J., Wood, N., Mueller-Pfeiffer, C., Milad, M. R., ... Orr, S. P. (2016). Delayed extinction fails to reduce skin conductance reactivity to fear-conditioned stimuli: Delayed extinction fails to reduce reactivity. Psychophysiology, 53(9), 1343-1351. doi: 10.1111/psyp.12687

Golkar, A., Bellander, M., Olsson, A., \& Öhman, A. (2012). Are fear memories erasable?-Reconsolidation of learned fear with fear-relevant and fear-irrelevant stimuli. Frontiers in Behavioral Neuroscience, 6, 1-10. doi: 10.3389/fnbeh.2012.00080

Grillon, C. (2002). Associative learning deficits increase symptoms of anxiety in humans. Biological Psychiatry, 51(11), 851-858. doi: 10.1016/S0006-3223(01)013701

Grillon, C., Baas, J. P., Lissek, S., Smith, K., \& Milstein, J. (2004). Anxious responses to predictable and unpredictable aversive events. Behavioral Neuroscience, 118(5), 916-924. doi: 10.1037/07357044.118.5.916

Haaker, J., Golkar, A., Hermans, D., \& Lonsdorf, T. B. (2014). A review on human reinstatement studies: An overview and methodological challenges. Learning \& Memory, 21(9), 424-440. doi: 10.1101/lm.036053.114

Johnson, D. C., \& Casey, B. J. (2015). Extinction during memory reconsolidation blocks recovery of fear in adolescents. Scientific Reports, 5(1). doi: 10.1038/srep08863

Kaczkurkin, A. N., Burton, P. C., Chazin, S. M., Manbeck, A. B., Espensen-Sturges, T., Cooper, S. E., ... Lissek, S. (2016). Neural substrates of overgeneralized conditioned fear in PTSD. American Journal of Psychiatry, 174(2), 125-134. doi: 10.1176/appi.ajp.2016.15121549

Kindt, M., \& Soeter, M. (2013). Reconsolidation in a human fear conditioning study: A test of extinction as updating mechanism. Biological Psychology, 92(1), 43-50. doi: 10.1016/j.biopsycho.2011.09.016

Kindt, M., Soeter, M., \& Vervliet, B. (2009). Beyond extinction: Erasing human fear responses and preventing the return of fear. Nature Neuroscience, 12(3), 256-258. doi: 10.1038/nn.2271

Klucken, T., Kruse, O., Schweckendiek, J., Kuepper, Y., Mueller, E. M., Hennig, J., \& Stark, R. (2016). No evidence for blocking the return of fear by disrupting reconsolidation prior to extinction learning. Cortex, 79, 112-122. doi: 10.1016/j.cortex.2016.03.015
Kredlow, M. A., Orr, S. P., \& Otto, M. W. (2018a). Exploring the boundaries of post-retrieval extinction in healthy and anxious individuals. Behaviour Research and Therapy, 108, 45-57. doi: 10.1016/j.brat.2018.06.010

Kredlow, M. A., Orr, S. P., \& Otto, M. W. (2018b). Who is studied in de novo fear conditioning paradigms? An examination of demographic and stimulus characteristics predicting fear learning. International Journal of Psychophysiology, 130, 21-28. doi: 10.1016/j.ijpsycho.2018.05.008

Kull, S., Müller, B. H., Blechert, J., Wilhelm, F. H., \& Michael, T. (2012). Reinstatement of fear in humans: Autonomic and experiential responses in a differential conditioning paradigm. Acta Psychologica, 140(1), 4349. doi: 10.1016/j.actpsy.2012.02.007

LeDoux, J. E. (2014). Coming to terms with fear. Proceedings of the National Academy of Sciences, 111(8), 2871-2878. doi: 10.1073/pnas.1400335111

Lee, J. L. C., Nader, K., \& Schiller, D. (2017). An update on memory reconsolidation updating. Trends in Cognitive Sciences, 21(7), 531-545. doi: 10.1016/j.tics.2017.04.006

Liu, J., Zhao, L., Xue, Y., Shi, J., Suo, L., Luo, Y., ... Lu, L. (2014). An unconditioned stimulus retrieval extinction procedure to prevent the return of fear memory. Biological Psychiatry, 76(11), 895-901. doi: 10.1016/j.biopsych.2014.03.027

Lonsdorf, T. B., Menz, M. M., Andreatta, M., Fullana, M. A., Golkar, A., Haaker, J., ... Merz, C. J. (2017). Don't fear "fear conditioning": Methodological considerations for the design and analysis of studies on human fear acquisition, extinction, and return of fear. Neuroscience \& Biobehavioral Reviews, 77, 247-285. doi: 10.1016/j.neubiorev.2017.02.026

Meir Drexler, S., Merz, C. J., Hamacher-Dang, T. C., Marquardt, V., Fritsch, N., Otto, T., \& Wolf, O. T. (2014). Effects of postretrieval-extinction learning on return of contextually controlled cued fear. Behavioral Neuroscience, 128(4), 474-481. doi: $10.1037 / \mathrm{a} 0036688$

Monfils, M.-H., Cowansage, K. K., Klann, E., \& LeDoux, J. E. (2009). Extinction-reconsolidation boundaries: key to persistent attenuation of fear memories. Science, 324(5929), 951-955. doi: 10.1126/science.1167975

Olsson, A., Ebert, J. P., Banaji, M. R., \& Phelps, E. A. (2005). The Role of Social Groups in the Persistence of Learned Fear. Science, 309(5735), 785-787. doi: 10.1126/science. 1113551

Oyarzún, J. P., Lopez-Barroso, D., Fuentemilla, L., Cucurell, D., Pedraza, C., Rodriguez-Fornells, A., \& de Diego-Balaguer, R. (2012). Updating fearful memories with extinction training during reconsolidation: A human study using auditory aversive stimuli. PLoS ONE, 7(6), e38849. doi: 


\subsection{1/journal.pone.0038849}

Pavlov, I. (1927). Conditioned reflexes: An investigation of the physiological activity of the cerebral cortex. London: Translated and edited by G. V. Anrep. Oxford University Press.

Rescorla, R. A. (1988). Pavlovian conditioning: It's not what you think it is. American Psychologist, 43(3), 151-160. doi: 10.1037/0003-066X.43.3.151

Rescorla, R. A., \& Heth, C. D. (1975). Reinstatement of fear to an extinguished conditioned stimulus. Journal of Experimental Psychology: Animal Behavior Processes, 1(1), 88-96. Doi: 10.1037/0097-7403.1.1.88

Schiller, D., Cain, C. K., Curley, N. G., Schwartz, J. S., Stern, S. A., LeDoux, J. E., \& Phelps, E. A. (2008). Evidence for recovery of fear following immediate extinction in rats and humans. Learning \& Memory, 15(6), 394-402. doi: 10.1101/lm.909208

Schiller, D., Kanen, J. W., LeDoux, J. E., Monfils, M.-H., \& Phelps, E. A. (2013). Extinction during reconsolidation of threat memory diminishes prefrontal cortex involvement. Proceedings of the National Academy of Sciences, 110(50), 20040-20045. doi: 10.1073/pnas.1320322110

Schiller, D., Monfils, M.-H., Raio, C. M., Johnson, D. C., LeDoux, J. E., \& Phelps, E. A. (2010). Preventing the return of fear in humans using reconsolidation update mechanisms. Nature, 463(7277), 49-53. doi: 10.1038/nature08637

Schiller, D., Raio, C. M., \& Phelps, E. A. (2012). Extinction training during the reconsolidation window prevents the recovery of fear. Journal of Visualized Experiments, 24(66), e3893. doi: 10.3791/3893

Soeter, M., \& Kindt, M. (2010). Dissociating response systems: Erasing fear from memory. Neurobiology of Learning and Memory, 94(1), 30-41. doi: 10.1016/j.nlm.2010.03.004

Soeter, M., \& Kindt, M. (2011). Disrupting reconsolidation: Pharmacological and behavioral manipulations. Learning \& Memory, 18(6), 357-366. doi: 10.1101/lm.2148511

Sokol, N., \& Lovibond, P. F. (2012). Cross-US reinstatement of human conditioned fear: Return of old fears or emergence of new ones? Behaviour Research and Therapy, 50(5), 313-322. doi: 10.1016/j.brat.2012.02.005

Spence, K. W., Haggard, D. F., \& Ross, L. E. (1958). UCS intensity and the associative (habit) strength of the eyelid CR. Journal of the Experimental Psychology, 55(5), 404-411. doi: 10.1037/h0048257

Steinfurth, E. C. K., Kanen, J. W., Raio, C. M., Clem, R. L., Huganir, R. L., \& Phelps, E. A. (2014). Young and old Pavlovian fear memories can be modified with extinction training during reconsolidation in humans. Learning \& Memory, 21(7), 338-341. doi:

\section{$10.1101 / \mathrm{lm} .033589 .113$}

Thompson, A., \& Lipp, O. V. (2017). Extinction during reconsolidation eliminates recovery of fear conditioned to fear-irrelevant and fear-relevant stimuli. Behaviour Research and Therapy, 92, 1-10. doi: 10.1016/j.brat.2017.01.017

Vervliet, B., Craske, M. G., \& Hermans, D. (2013). Fear extinction and relapse: State of the art. Annual Review of Clinical Psychology, 9(1), 215-248. doi: 10.1146/annurev-clinpsy-050212-185542

Zeidan, M. A., Lebron-Milad, K., Thompson-Hollands, J., Im, J. J. Y., Dougherty, D. D., Holt, D. J., ... Milad, M. R. (2012). Test-retest reliability during fear acquisition and fear extinction in humans: reliability of fear conditioning across tests. CNS Neuroscience \& Therapeutics, 18(4), 313-317. doi: 10.1111/j.17555949.2011.00238.x

Zuccolo, P. F., \& Hunziker, M. H. L. (2019). A review of boundary conditions and variables involved in the prevention of return of fear after post-retrieval extinction. Behavioural Processes, 162, 39-54. doi: 10.1016/j.beproc.2019.01.011

Submitted on: 03/14/2019 Accept on: 06/27/2019 